\title{
Comparison of the effects of low dose methylprednisolone and metoclopramide on nausea and vomiting and respiratory complications after adenotonsillectomy in children
}

\author{
Ali Bestemi Kepekci, MD*1, Bugra Subasi, MD², Ahmet Hamdi Kepekci, MD³, \\ Aziz Yarbil, MD ${ }^{4}$ \\ 1 - Department of Anesthesia, Vocational Health High School, Istanbul Yeni Yuzyil University, Istanbul, Turkey; ORCID: 0000-0002- \\ 5215-9545 \\ 2 - Department of Otorhinolaryngology, Faculty of Medicine, Kutahya University of Health Sciences, Kutahya, Turkey; ORCID: \\ 0000-0002-7666-612X; E-mail: drbugrasubasi@hotmail.com
}

3 - Department of Audiometry, Vocational Health High School, Istanbul Yeni Yuzyil University, Istanbul, Turkey; ORCID: 00000002-5332-5234; E-mail: ahmethamdi.kepekci@yeniyuzyil.edu.tr

4 - Department of Anesthesiology and Reanimation, Kilis State Hospital, Kilis, Turkey; ORCID: 0000-0002-9676-7008; E-mail: ayarbil@gmail.com

Correspondence: Ali Bestemi KEPEKÇi, MD, Maltepe Mahallesi, Yılanlı Ayazma Caddesi, No: 26 P.K. 34010 Cevizlibağ / Zeytinburnu / İstanbul, Turkey; Phone: +905322653747; Fax: +902124814058; Mail: alibestemi.kepekci@yeniyuzyil.edu.tr

\section{Abstract}

Aim: Since tonsillectomies and/or adenoidectomies performed in the pediatric age group under general anesthesia have a high rate of postoperative nausea and vomiting (PONV), the practice of using prophylactic antiemetic drugs is common. This study aimed to compare the benefits of systemic administration of a low dose of inj. methylprednisolone $1 \mathrm{mg} / \mathrm{kg}$ with inj. metoclopramide $0.15 \mathrm{mg} / \mathrm{kg}$ IV for the prevention of PONV in children undergoing adenotonsillectomy.

Methodology: In this study, the files of children undergone adenotonsillectomy from August 2015 to January 2018 in our hospital were analyzed retrospectively. 408 children aged 4-12 years were included in the study. Patients who were given methylprednisolone $1 \mathrm{mg} / \mathrm{kg}$ IV as premedication were placed in Group $\mathrm{P}$, and patients who received metoclopramide $0.15 \mathrm{mg} / \mathrm{kg}$ were grouped as Group $\mathrm{M}$. Effects on PONV, vomiting episodes, oral intake time, postoperative analgesic requirement, postoperative respiratory complications, and drug side effects were recorded.

Results: Vomiting rates between $1-4$ hrs (late period) were $11.0 \%$ in Group M ( $n=22$ ); It was 3.8\% ( $n=8)$ in Group $P$. In the late period, a significant difference was found between the two groups in terms of nausea and vomiting ( $p$ $=0.02, p=0.07$, respectively). In Group $M$, the incidence of respiratory complications was also higher in the postoperative period compared to Group P. Postoperative acetaminophen requirement increased significantly in group $\mathrm{M}$ compared to Group $\mathrm{P}(\mathrm{p}=0.006)$.

Conclusion: Prophylactic use of a single dose of methylprednisolone $1 \mathrm{mg} / \mathrm{kg}$ IV during the preoperative period was more effective in reducing the incidence of late postoperative vomiting compared to metoclopramide and led to earlier tolerance of oral intake. In addition to its anti-inflammatory properties and antiemetic effects, low-dose methylprednisolone is also useful for prevention of respiratory complications.

Key words: Methylprednisolone; Metoclopramide Hydrochloride; PONV; Respiratory complications; Tonsillectomy 
Citation: Kepekci AB, Subasi B, Kepekci AH, Yarbil A. Comparison of the effects of low dose methylprednisolone and metoclopramide on nausea and vomiting and respiratory complications after adenotonsillectomy in children. Anaesth. pain intensive care 2020;24(5):544-551

Received: 29 July 2020, Reviewed: 22 September 2020, Revised: 30 August 2020, Accepted: 2 October 2020

\section{Introduction}

The most common surgical procedures in pediatric patients worldwide are tonsillectomy and/or adenoidectomy. ${ }^{1}$ Postoperative nausea and vomiting (PONV) is a common cause of morbidity in children and increased length of hospital stay. PONV is defined as nausea and/or vomiting seen in the first 24 hours after the operation. ${ }^{2}$

It is reported that PONV is seen in as much as $60-70 \%$ of the patients, when no antiemetic is administered in tonsillectomy operations performed in the pediatric age group. ${ }^{3}$ In addition to prolonging the time to discharge from the hospital after the scheduled tonsillectomy, PONV has also been shown to lead to increased risk of bleeding, aspiration of stomach contents, dehydration, and electrolyte disturbances. Since it is more common in children, a prophylactic antiemetic is widely used as premedication in children.

Tonsillectomies and/or adenoidectomies in children may also cause a higher incidence of respiratory complications varying between 1.4 and $5 \% .^{4}$ Perioperative steroids may decrease pharyngeal swelling and the risk of airway compromise.

Glucocorticoids have been used as antiemetics in cancer patients who received chemotherapy for the first time. These have been used in laparoscopic and gynecological surgery in adults, and in children undergoing tonsillectomy and strabismus surgery. The mechanism of action of steroids is not known exactly; it is advocated that these exert their antiemetic effect by inducing prostaglandin antagonism and endorphin release, reducing the transformation of 5-HT3 in the brain. $^{5}$

There are many studies in the literature showing that postoperative edema and pain decreased after tonsil surgery and increased oral intake due to the antiemetic and anti-inflammatory properties of glucocorticoids. ${ }^{6}$ However, data on the safety of prophylactic dexamethasone are not conclusive. ${ }^{7}$

Methylprednisolone has been shown to be more effective than dexamethasone in treating acute respiratory diseases. It can quickly and effectively control airway inflammation, relieve spasm, thus shortness of breath and wheezing. The effect of methylprednisolone on the respiratory tract appears to be superior to dexamethasone and has been recommended as a first-line treatment for acute respiratory symptoms. ${ }^{8}$ However, there are no studies comparing the use of methylprednisolone with other antiemetics for PONV prophylaxis after adenotonsillectomy in children. The main purpose of this study was to evaluate the effects of systemic administration of low-dose methylprednisolone on the prevention of PONV in children after adenotonsillectomy and potential respiratory complications in children with tonsillectomy, when compared to metoclopramide.

\section{Methodology}

In this retrospective study, patient record files of all children with ASA I and ASA II, aged between 4-12 years, who underwent adenotonsillectomy at our hospital from 1 August 2015 to 31 January 2018, were analyzed. Noting the past history of use of antiemetics, steroids, antihistamines, or psychoactive drugs in 24 hours prior to surgery, the children allergic to the drugs used and who had previously had a history of PONV were excluded from the study. The study was approved by Istanbul Yeni Yuzyil University Ethics Committee (The number is 2018/4 dated 2 April 2018 Informed consent was not obtained due to the retrospective nature of the study.

In our hospital, solid food intake is restricted 6 hours before as routine preoperative preparation of all children before anesthesia. Clear fluids are allowed till 2 hours. Vascular access was performed in all patients. After the first entry into the operating room, midazolam $0.05 \mathrm{mg} / \mathrm{kg}$ IV was given for premedication, and standard monitoring (heart rate, noninvasive blood pressure, and pulse oxygen saturation) was applied. Anesthesia was induced with inj. fentanyl $1 \mu \mathrm{g} / \mathrm{kg}$ and inj. propofol $2 \mathrm{mg} / \mathrm{kg}$ IV. After the administration of rocuronium $0.6 \mathrm{mg} / \mathrm{kg}$ IV, endotracheal intubation was performed. Anesthesia was maintained with $60 \%$ N2O- $40 \%$ O2 and $2-4 \%$ 
sevoflurane. All children were infused maintenance dose of $1 / 3$ isodex $(3.33 \%$ dextrose $+0.3 \%$ sodium chloride solution) before the start of surgery and during anesthesia.

While the dissection technique was used for palatine tonsils, adenoidectomies were performed with Beckman curette.

The patients were divided into two groups. Group $\mathrm{P}$ patients received low-dose methylprednisolone (1 $\mathrm{mg} / \mathrm{kg}$ ) IV as premedication and patients in Group M received inj. metoclopramide $0.15 \mathrm{mg} / \mathrm{kg}$ (maximum $10 \mathrm{mg}$ ) IV. When the surgery was over, the stomach contents of all children were evacuated with the help of an orogastric catheter prior to extubation. Inj. neostigmine $0.05 \mathrm{mg} / \mathrm{kg}$ and atropine $0.02 \mathrm{mg} / \mathrm{kg}$ IV were administered to reverse the neuromuscular block before extubation.

All children received standard monitoring in the postoperative anesthesia care unit (PACU Postoperative follow-up of the patients was planned in two periods as 'early' and 'late period'. Patients were followed up in the PACU for the first 1 hour - the 'early period'; the next 3 hours they were followed in the ward - the 'late period'. The frequency of PONV was recorded.

After extubation, the pain was evaluated at 0 and 15 min and at 1st, 2nd, and 4th hours by Wong-Baker Faces pain score. In terms of post-op analgesia, acetaminophen $(1.5 \mathrm{ml} / \mathrm{kg}$, IV) was used when score was $>6$. Analgesic consumption was recorded in the postop period. The patients were given a soft diet during their stay in the hospital, and intravenous fluids continued until adequate nutrition was provided. Time to oral intake was recorded.

The incidence of postoperative respiratory complications e.g., severe hypoxemia (oxygen saturation $<70 \%)$, oxygen desaturation $(71 \%-90 \%)$, reintubation, upper-airway obstruction, the need of continuous positive airway pressure via anesthesia machine, the need of bronchodilators or supplemental oxygen) between the two groups, was recorded. Besides, postoperative bleeding and drug side effects (fever, headache, redness, urticarial etc.) were recorded. The operation time was noted.

\subsection{Statistical analysis}

Statistical analysis was performed using SPSS (Statistical Package for Social Sciences) for Windows 16.0. The parametric data were presented as mean \pm standard deviation (mean $\pm \mathrm{SD}$ ), non-parametric data as median $(25 \%-75 \%)$, at least-most, and $\mathrm{n}(\%$ Parametric data were compared with Student's t-test. Non-parametric data were analyzed with Man Whitney-U, chi-square, or Fisher's chi-square tests. Intra-group comparisons were performed by the paired Student t-test. $\mathrm{p}<0.05$ was considered significant.

\section{Results}

The demographic data of the patients and operations of the patients is given in Table 1. There was no statistically significant difference between groups regarding age, gender, ASA scores, weight, and operation time. The comparative frequency of postoperative nausea alone, or nausea + vomiting in both groups is shown in Table 2. There was no significant difference between the groups in terms of both nausea and vomiting within the first hour after the operation. We compared frequency of vomiting between 1-4 hours (late period); it was $11.0 \%(\mathrm{n}=22)$ in Group $\mathrm{M}$, and $3.8 \%(\mathrm{n}=8)$ in Group $\mathrm{M}$. The incidence of nausea was observed in $8(4 \%)$ in Group $\mathrm{M}$; and $21(10.0 \%)$ patients in Group $\mathrm{M}$ during this period. Significant differences were found between the two groups in terms of both nausea and vomiting in the 'late period' ( $\mathrm{p}=0.02$, and $\mathrm{p}=0.07$ respectively

In Table 3, data about pain scores, time to oral intake, and the need for additional analgesia or the interventions required are listed. The acetaminophen requirement was significantly higher in Group $M$ compared to Group P ( $\mathrm{p}=0.006$ ). The time to oral intake was $3.11 \pm 0.60 \mathrm{hrs}$ in Group $\mathrm{M}$ and $1.88 \pm 0.78$ hrs in Group $\mathrm{P}(\mathrm{p}=0.002)$. The difference was statistically significant. As seen in Table 4, there was a significant difference between the two groups in the presence of side effects. However, in Group M, extrapyramidal findings were not observed in any patient. No postoperative bleeding was reported in any of our patients. Statistical significance was found between the two groups in terms of respiratory complications, (Table 5), being more common in Group $\mathrm{M}$ than in Group $\mathrm{P}$ patients. Fifteen patients in Group $\mathrm{M}$ developed severe hypoxemia requiring intervention $(\mathrm{p}=0.043)$. 


\section{Table 1: Demographic data and operation knowledge}

\begin{tabular}{|c|c|c|c|}
\hline Parameters & $\begin{array}{l}\text { Group } P \\
(n=200)\end{array}$ & $\begin{array}{l}\text { Group M } \\
(n=208)\end{array}$ & $\mathbf{p}$ \\
\hline $\mathrm{N}$ (female/male) & $208(120 / 88)$ & $200(108 / 92)$ & 0.430 \\
\hline Age (year) & $7.08 \pm 2.64$ & $6.60 \pm 2.56$ & 0.297 \\
\hline Body weight (kg) & $21.14 \pm 9.25$ & $20.71 \pm 7.47$ & 0.732 \\
\hline Operation time (min) & $31.54 \pm 12.95$ & $31.22 \pm 10.77$ & 0.528 \\
\hline
\end{tabular}

\section{Table 2: Frequency of PONV}

\begin{tabular}{|c|c|c|c|}
\hline PONV & $\begin{array}{l}\text { Group P } \\
(n=200)\end{array}$ & $\begin{array}{l}\text { Group M } \\
(n=208)\end{array}$ & $\mathbf{p}$ \\
\hline \multicolumn{4}{|l|}{ Vomiting Early (0-1 h) } \\
\hline - $\quad$ Once & $24(11.5 \%)$ & $28(14 \%)$ & 0.463 \\
\hline - Multiple & $3(1.5 \%)$ & $7(3.4 \%)$ & 0.339 \\
\hline \multicolumn{4}{|l|}{ Vomiting Late (1-4 h) } \\
\hline - Once & $8(3.8 \%)$ & $22(11.0 \%)$ & ${ }^{*} 0.07$ \\
\hline - $\quad$ Multiple & $1(0.05 \%)$ & $9(4.3 \%)$ & ${ }^{*} 0.02$ \\
\hline \multicolumn{4}{|l|}{ Nausea Early (0-1 h) } \\
\hline - Once & $33(16.5 \%)$ & $45(21.6 \%)$ & 0.209 \\
\hline - $\quad$ Multiple & $11(5.5 \%)$ & $20(9.6 \%)$ & 0.136 \\
\hline \multicolumn{4}{|l|}{ Nausea Late (1-4 h) } \\
\hline - Once & $8(4.0 \%)$ & $21(10.0 \%)$ & ${ }^{*} 0.02$ \\
\hline - Multiple & $1(0.5 \%)$ & $13(6.3 \%)$ & ${ }^{*} 0.002$ \\
\hline
\end{tabular}

Table 3: Postoperative Wong-Baker Faces rating scale, acetaminophen consumption and oral intake time

\begin{tabular}{|c|c|c|c|}
\hline Variable & $\begin{array}{l}\text { Group M } \\
(n=208)\end{array}$ & $\begin{array}{l}\text { Group } P \\
(n=200)\end{array}$ & $\mathbf{P}$ \\
\hline \multicolumn{4}{|l|}{ Wong-Baker Faces pain rating score } \\
\hline Post-op 15 min & $5.58 \pm 2.61$ & $4.96 \pm 2.53$ & 0.181 \\
\hline Post-op 1st hour & $4.77 \pm 1.48$ & $2.66 \pm 0.70$ & $0.007^{*}$ \\
\hline Post-op 2 hours & $3.22 \pm 0.66$ & $2.44 \pm 0.52$ & $0.008^{*}$ \\
\hline Post-op 4 hours & $2.88 \pm 0.33$ & $1.77 \pm 0.66$ & $0.003^{*}$ \\
\hline Acetaminophen consumption (ml/kg) & $4.42 \pm 1.51$ & $2.28 \pm 0.48$ & $0.006^{*}$ \\
\hline Time to oral intake (hrs) & $3.11 \pm 0.60$ & $1.88 \pm 0.78$ & $0.002^{*}$ \\
\hline
\end{tabular}

Group $M=$ Metoclopramide group; Group $P=$ Methylprednisolone group; * $p<0.05$

\section{Discussion}

In this study, we retrospectively evaluated the benefits of low dose $(1 \mathrm{mg} / \mathrm{kg})$ methylprednisolone in comparison to metoclopramide in our institution for the prevention of PONV and respiratory complications in children after adenotonsillectomy.

\subsection{PONV}

Nowadays, the development of better surgical 
Table 4: Comparative drug side effects

\begin{tabular}{|c|c|c|c|}
\hline Side effects & $\begin{array}{l}\text { Group M } \\
(n=208)\end{array}$ & $\begin{array}{l}\text { Group } P \\
(n=200)\end{array}$ & $\mathbf{p}$ \\
\hline Dizziness & $8(3.8 \%)$ & 0 & ${ }^{\star} 0.007$ \\
\hline Drowsiness & $15(7.2 \%)$ & 0 & ${ }^{*}<0.001$ \\
\hline Fatigue & $8(3.8 \%)$ & 0 & ${ }^{*} 0.007$ \\
\hline Fever & 0 & $8(4.0 \%)$ & ${ }^{\star} 0.003$ \\
\hline Facial flushing & 0 & $6(3.0 \%)$ & ${ }^{*} 0.013$ \\
\hline Headache & $8(3.8 \%)$ & $9(4.5 \%)$ & 0.808 \\
\hline Bleeding & 0 & 0 & $\ldots \ldots$ \\
\hline
\end{tabular}

\begin{tabular}{|c|c|c|c|}
\hline Parameter & $\begin{array}{l}\text { Group M } \\
(n=208)\end{array}$ & $\begin{array}{l}\text { Group P } \\
(n=200)\end{array}$ & $\mathbf{p}$ \\
\hline Severe hypoxemia (oxygen saturation < 70\%) (n) & 15 & 6 & *0.043 \\
\hline Oxygen desaturation (saturation $71 \%-90 \%$ ) (n) & 25 & 7 & ${ }^{*} 0.001$ \\
\hline Reintubation (n) & 0 & 0 & $\ldots$ \\
\hline Upper-airway obstruction (n) & 15 & 6 & ${ }^{*} 0.043$ \\
\hline Bradycardia (n) & 2 & 0 & 0.240 \\
\hline Continuous Positive Airway Pressure (n) & 15 & 6 & ${ }^{*} 0.043$ \\
\hline Salbutamol by inhalation (n) & 15 & 6 & ${ }^{*} 0.043$ \\
\hline Supplemental oxygen (n) & 40 & 13 & ${ }^{*}<0.001$ \\
\hline
\end{tabular}

techniques, as well as the introduction of new anesthetic drugs and modern anesthesia devices, have reduced the frequency of many peri-operative complications. However, the occurrence of PONV has still not been entirely controlled. ${ }^{9}$ About $30 \%$ of all patients undergoing surgery have PONV. ${ }^{10}$ Metoclopramide is one of the oldest drugs widely used as an antiemetic. ${ }^{11}$ Its antiemetic efficacy has been the subject of many recent studies. ${ }^{11-13}$ It hastens the gastrointestinal transit time, which results in a reduced incidence of PONV. ${ }^{14}$

The most commonly used prophylactic drugs for PONV are steroids. These are the most researched drugs for the prevention of PONV because of their low cost and low side effects. ${ }^{15}$ Intravenous metoclopramide has been found to have a similar effect to 5-HT3 receptor antagonists for early PONV. ${ }^{16}$ Methylprednisolone is a readily available drug with a large number of preparations. Methylprednisolone, which is known for its anti-inflammatory activity, has been shown to be used in the prophylaxis of vomiting in many studies in both adults and children. ${ }^{17}$ Our study is important in this regard, as it demonstrates the efficacy of methylprednisolone in preventing vomiting after adenotonsillectomy operations.

In his study, Weren $M$. demonstrated that the prophylactic use of methylprednisolone and dexamethasone in late-term PONV was more effective than a placebo, and steroids were more effective than early PONV prevention in the prevention of late PONV. ${ }^{18}$

In our study, the frequency of PONV in children with tonsillectomy was compared during early and late periods. Although similar results were detected in group $\mathrm{M}$ and group $\mathrm{P}$ in the early period, methylprednisolone provided acceptable prophylaxis of PONV in the late period. Our data demonstrate that low dose methylprednisolone resulted in a significant 
reduction in the number of patients suffering from PONV within the 1-4 $\mathrm{h}$ when compared to metoclopramide.

Ise et al. in their study on children taking cancer chemotherapy, found methylprednisolone as the most effective antiemetic in preventing nausea and vomiting (89\%), followed by domperidone (51\%) and metoclopramide $(17 \%) .{ }^{19}$

The use of $1 \mathrm{mg} / \mathrm{kg}$ methylprednisolone alone in children before tonsillectomy was found to have the same effect in reducing PONV incidence and episodes during PACU (early period) and the ward (late period) follow-up without additional antiemetics.

1.2. Respiratory complications, pain and, oral intake time

Metoclopramide has been reported to cause acute dystonic reactions with concomitant respiratory failure as a result of airway obstruction..$^{20,21}$ The risk of dyskinesia and extrapyramidal symptoms is not very high with metoclopramide. But the higher the dose, the higher the risk. ${ }^{22}$

In our study, metoclopramide was used at the recommended dosage ranges of $0.1 \mathrm{mg} / \mathrm{kg} \mathrm{IV}$, to a maximum of $10 \mathrm{mg}{ }^{7}$

Adenotonsillar surgery may cause laryngopharyngeal injury, resulting in inflammation due to surgical techniques. This can lead to glottic or supraglottic narrowing, which manifests as stridor, or respiratory distress after surgery. Glucocorticoids have potent anti-inflammatory properties, ${ }^{23}$ besides having analgesic effects. As seen in Table 5, our study demonstrates that respiratory complications were significantly less in the methylprednisolone group compared with the metoclopramide group. Pain is also considered a risk factor in the presence of PONV, as stress can induce nausea. ${ }^{24} \mathrm{PONV}$ prophylaxis as well as the pain relief feature of the chosen drug is therefore, important.

A single dose of methylprednisolone has been shown to cause 24-hour analgesia. ${ }^{25} \mathrm{We}$ found that preoperative low-dose methylprednisolone improves pain scores, reduces analgesic requirements, provides earlier oral fluid intake, and improves postoperative swallowing and time to oral intake. The results can be related to the reduction of local edema and painreducing anti-inflammatory effects of methylprednisolone.

\subsection{Drug side effects}

Extrapyramidal symptoms, especially acute dystonic reactions, are the most common side effects of metoclopramide. ${ }^{26}$ In our study, there were twelve patients in Group $\mathrm{M}$, who experienced transient drowsiness or dizziness, and all symptoms resolved without treatment. No patient in our study develop extrapyramidal symptoms.

The most common side effect of the methylprednisolone has been flushing of the face, fever, a metallic taste, and headache. The long-term administration of corticosteroids is definitely associated with adverse events.

In our study, fever in the postoperative period was noted in six patients in Group P. Headache was noted in $4.5 \%$ vs. $3.80 \%$ in the Group $\mathrm{M}$ and Group $\mathrm{P}$ respectively $(\mathrm{p}=0.808)$. The percentage of facial flushing in Group P was 3\%, while in Group M it was not seen in any patient $(p=0.013)$. The symptoms resolved without any treatment.

The fact that all operations were performed by the same surgical team using the same method and high number of cases are the strengths of the study. The results are consistent with the literature. Since the study was planned retrospectively, the most important limitation is that not all factors affecting the results may have been completely excluded.

\section{Conclusion}

We conclude that the single preoperative dose of 1 $\mathrm{mg} / \mathrm{kg}$ methylprednisolone IV can reduce the frequency of late postoperative nausea/vomiting better than the use of metoclopramide. Its antiemetic effects, in addition to the analgesic properties, make it particularly useful for respiratory complications. Although single-dose corticosteroids are safe to use, further studies should be performed with longer follow-up.

\section{Conflict of Interest}

The authors declare no conflict of interest.

\section{Financial Disclosure}

The authors declare that this study received no financial support. 


\section{References}

1. Bolton C, Myles P, Nolan T, Sterne J. Prophylaxis of postoperative vomiting in children undergoing tonsillectomy: a systematic review and meta-analysis. $\mathrm{Br}$ $J$ Anaesth. 2006;97(5):593-604. [PubMed] DOI: $10.1093 /$ bja/ael256

2. McCracken $G$, Houston $P$, Lefebvre G. Guideline for the management of postoperative nausea and vomiting. $J$ Obstet Gynaecol Can. 2008:30(7):600-7. [PubMed] DOI: $10.1016 / \mathrm{s} 1701-2163(16) 32895-\mathrm{x}$

3. Jensen $A B$, Christiansen $D B$, Coulthard $K$, Wilkins $A$, Roberts $\mathrm{G}$, Walt $\mathrm{JH}$, et al. Tropisetron reduces postoperative vomiting in children undergoing tonsillectomy. Pediatr Anesth. 2000;10(1):69-75. [PubMed] DOI: 10.1046/j.1460-9592.2000.00401.x

4. Hill CA, Litvak A, Canapari C, Cummings B, Collins C, Keamy DG, et al. A pilot study to identify pre-and perioperative risk factors for airway complications following adenotonsillectomy for treatment of severe pediatric OSA. Int J Pediatr Otorhinolaryngol. 2011;75(11):138590. [PubMed] DOI: 10.1016/j.jporl.2011.07.034

5. Watcha MF, White PF. Postoperative nausea and vomiting. Its etiology, treatment, and prevention. Anesthesiology. 1992;77(1):162-84. [PubMed] [Free full text] DOI: 10.1097/00000542-199207000-00023

6. Özbakış Akkurt Ç, İnanoğlu K, Okuyucu Ş, Turhanoğlu $S$, Akoğlu E, Kireçci N. Comparison of the Effects of Methylprednisolone and Dexamethasone on Preventing Vomiting After Tonsillectomy in Children. Turk J Anaesthesiol Reanim. 2008;36(5):317-23.

7. Tateosian VS, Champagne K, Gan TJ. What is new in the battle against postoperative nausea and vomiting? Best Pract Res Clin Anaesthesiol. 2018;32(2):137-48. [PubMed] DOI: 10.1016/j.bpa.2018.06.005

8. Li H, He G, Chu H, Zhao L, Yu H. A step-wise application of methylprednisolone versus dexamethasone in the treatment of acute exacerbations of COPD. Respirology. 2003;8(2):199-204. [PubMed] DOI: 10.1046/j.14401843.2003.00468.x

9. Romundstad L, Breivik H, Roald H, Skolleborg K, Haugen T, Narum J, et al. Methylprednisolone reduces pain, emesis, and fatigue after breast augmentation surgery: a single-dose, randomized, parallel-group study with methylprednisolone $125 \mathrm{mg}$, parecoxib $40 \mathrm{mg}$, and placebo. Anesth Analg. 2006;102(2):418-25. [PubMed] DOI: 10.1213/01.ane.0000194358.46119.e1

10. Gautam S, Agarwal A, Das PK, Agarwal A, Kumar S, Khuba S. Evaluation of the efficacy of methylprednisolone, etoricoxib and a combination of the two substances to attenuate postoperative pain and PONV in patients undergoing laparoscopic cholecystectomy: a prospective, randomized, placebocontrolled trial. Korean j Pain. 2014;27(3):278. [PubMed] [Free full text] DOI: 10.3344/kjp.2014.27.3.278

11. Moezzi M, Delirrooyfard A, Motamed H, Mortazavi MK. Antiemetic effects of metoclopramide with and without dexamethasone in children with minor head trauma: a single blind randomized clinical trial. Electronic physician. 2018;10(10):7307-13. [Free full rext] DOI: $10.19082 / 7307$

12. Chandrakar N, Lalwani J, Sahare K, Bandhu S. Use of Patient Controlled Analgesia Using IV Tramadol and IV Nalbuphine for Postoperative Pain Management after Major Abdominal Surgery-A Comparative Study. Int J Res Rev. 2016;3(5):43-53. [Free full text]

13. Kampo $S$, Afful AP, Mohammed S, Ntim M, Buunaaim $A D$, Anabah TW. Sub-hypnotic dose of propofol as antiemetic prophylaxis attenuates intrathecal morphineinduced postoperative nausea and vomiting, and pruritus in parturient undergoing cesarean section-a randomized control trial. BMC anesthesiology. 2019;19(1):177. [Free full text] DOI: 10.1186/s12871019-0847-y

14. Alonso-Campero $\mathrm{R}$, Bernardo-Escudero $\mathrm{R}$, de Jesús Francisco-Doce $M$, Cortes-Fuentes $M$, CastañedaHernandez G, Ortiz M. Bioequivalence Study of Metoclopramide Hydrochloride $10 \mathrm{mg}$ Tablets in Healthy Male Volunteers. J Bioequiv Availab. 2011;3(10):222-7. DOI:10.4172/JBB.1000090

15. Wang J-J, Ho S-T, Tzeng J-I, Tang C-S. The effect of timing of dexamethasone administration on its efficacy as a prophylactic antiemetic for postoperative nausea and vomiting. Anesth Analg. 2000;91(1):136-9. [PubMed] DOI: 10.1097/00000539-200007000-00025

16. Wallenborn J, Gelbrich G, Bulst D, Behrends K, Wallenborn $H$, Rohrbach $A$, et al. Prevention of postoperative nausea and vomiting by metoclopramide combined with dexamethasone: randomised double blind multicentre trial. Br Med J. 2006;333(7563):324. [PubMed] DOI: 10.1136/bmj.38903.419549.80

17. Gebbia V, Testa A, Valenza R, Cannata G, Tirrito ML, Gebbia N. Oral granisetron with or without methylprednisolone versus metoclopramide plus methylprednisolone in the management of delayed nausea and vomiting induced by cisplatin-based chemotherapy. A prospective randomized trial. Cancer. 1995;76(10):1821-8. [PubMed] DOI: 10.1002/10970142(19951115)76:10<1821::aidcncr2820761022>3.0.co;2-y

18. Weren $M$, Demeere J. Methylprednisolone vs. dexamethasone in the prevention of post-operative nausea and vomiting: a prospective, randomised, double-blind, placebo-controlled trial. Acta Anaesthesiol Belg. 2008;59(1):1. [PubMed]

19. Ise $T$, Ohira M, Omiya A, Hirose M, Shibata T. [Clinical evaluation of antiemetics for vomiting due to cancer chemotherapy in children]. Gan To Kagaku Ryoho. 1982 Jul;9(6):1108-18. [Paper in Japanese]. PMID: 6764113. [PubMed]

20. Rich WM, Abdulhayoglu G, DiSaia PJ. Methylprednisolone as an antiemetic during cancer chemotherapy-a pilot study. Gynecol Oncol. 1980;9(2):193-8. [PubMed] DOI: 10.1016/0090$8258(80) 90027-x$ 
21. Harris A. Cytotoxic-therapy-induced vomiting is mediated via enkephalin pathways. The Lancet. 1982;319(8274):714-6. [PubMed]

22. Yis U, Ozdemir D, Duman M, Unal N. Metoclopramide induced dystonia in children: two case reports. Eur $\mathrm{J}$ Emerg Med. 2005;12(3):117-9.

23. Schleimer R. An overview of glucocorticoid antiinflammatory actions. Eur J Clin Pharmacol. 1993;45(1):S3-S7. DOI: $10.1007 / B F 01844196$

24. Apfel CC, Korttila K, Abdalla M, Kerger H, Turan A Vedder I, et al. A factorial trial of six interventions for the prevention of postoperative nausea and vomiting. $\mathrm{N}$ prevention of postoperative nausea and vomiting. $\mathrm{N}$ Engl J Med. 2004;350(24):2441-51. [PubMed] DOI: 10.1056/NEJMoa032196

25. Romundstad L, Breivik H, Niemi G, Helle A, Stubhaug A. Methylprednisolone intravenously 1 day after surgery has sustained analgesic and opioid-sparing effects. Acta anaesthesiol Scand. 2004;48(10):1223-31. [PubMed] DOI: 10.1111/j.1399-6576.2004.00480.x

26. Veyrat-Follet C, Farinotti R, Palmer JL. Physiology of chemotherapy-induced emesis and antiemetic therapy.

Drugs. 1997;53(2):206-34.

[PubMed] 